\title{
Sobre chácaras, pântanos e roçados: aspectos sobre a formação da região industrial e operária de Niterói no início do século XX
}

On farms, swamps and small farms: conforming the industrial and working area of Niterói in the early 20th century

Sobre chacras, pantanos y rozados: aspectos sobre la formación de la región industrial y obrera de Niterói a principios del siglo XX

Sur les petites et moyennes fermes et et les marécages: aspects de la formation de la zone industrielle et ouvrière de Niteroi au début du 20ème siècle

\section{Luciana Pucu Wollmann}

\section{OpenEdition}

Journals

Edição electrónica

URL: http://journals.openedition.org/espacoeconomia/3328

DOI: $10.4000 /$ espacoeconomia.3328

ISSN: 2317-7837

Editora

Núcleo de Pesquisa Espaço \& Economia

Refêrencia eletrónica

Luciana Pucu Wollmann, « Sobre chácaras, pântanos e roçados: aspectos sobre a formação da região industrial e operária de Niterói no início do século XX », Espaço e Economia [Online], 12 | 2018, posto online no dia 14 julho 2018, consultado o 01 maio 2019. URL : http://journals.openedition.org/ espacoeconomia/3328; DOI : 10.4000/espacoeconomia.3328

Este documento foi criado de forma automática no dia 1 Maio 2019

(c) NUPEE 


\title{
Sobre chácaras, pântanos e roçados: aspectos sobre a formação da região industrial e operária de Niterói no início do século XX
}

On farms, swamps and small farms: conforming the industrial and working area

of Niterói in the early 20th century

Sobre chacras, pantanos y rozados: aspectos sobre la formación de la región

industrial y obrera de Niterói a principios del siglo XX

Sur les petites et moyennes fermes et et les marécages: aspects de la formation de la zone industrielle et ouvrière de Niteroi au début du 20ème siècle

\section{Luciana Pucu Wollmann}

\begin{abstract}
A cidade de Nictheroy precisa ainda de população. Grandes são os claros que se notam em suas ruas; pode-se afirmar que sessenta por cento da cidade esta despovoada. Povoal-a deve ser o empenho primordial. $\mathrm{Na}$ realização deste empenho, porem dever-se-a ter em vista crear uma população permanente, fixa, a ella ligada por laços de sincero affecto. (...) Como conseguil-o? De um lado: promovendo o alargamento da tendência fabril, visivelmente pronunciada; fomentando a creação de novas uzinas, pela concessão de favores subordinados a um vasto plano industrial, que assentaria na reducção de impostos e no fornecimento quase gratuito, de energia electrica; propagando e cimentando no operariado os princípios milagrosos do cooperativismo. De outro lado: fazendo realçar e aproveitando as bellezar naturaes da cidade.

(Paulo Pereira Alves. CD-ROM. UFF/ NDC/ CMF/ BN (org.). Relatório de Prefeitos de Niterói (1904-1977). Mensagem apresentada à Câmara Municipal de Nictheroy Nictheroy: Escola Typographica Salesiana, 1904. p. 4-5) ${ }^{1}$
\end{abstract}

No início do século XX, Niterói ainda exibia, segundo o recém-nomeado prefeito Paulo Alves, ares de "arraial sertanejo". Ruas sem pavimentação, iluminadas a gás, bondes puxados por burros, "quitandas volantes de roceiros" (Idem, p. 33), problemas com o abastecimento de água e coleta de esgotos, tratavam de conferir à cidade uma atmosfera 
incompatível com o seu estatuto de capital fluminense, então recentemente reconquistado ${ }^{2}$. No centro da cidade, onde os traçados urbanísticos que remontavam ao período imperial ainda prevaleciam³, habitações coletivas e "anti-higiênicas" proliferavam. Em condições semelhantes, centenas de trabalhadores aglomeravam-se em antigos casarões, cortiços e casas de cômodo nos bairros onde já era possível vislumbrar certa concentração industrial, como o Barreto e Ponta d'Areia.

2 No alvorecer da República, quando os projetos modernizantes para o país exasperavam os debates entre os defensores da "vocação agrícola" e àqueles que buscavam outras opções de desenvolvimento para o Brasil (CARONE, 1978), o engenheiro e empresário Paulo Alves imbuía-se da missão de modernizar a capital fluminense através de um programa de estímulo à industrialização nascente. Apesar de ter sido indicado pelo então Presidente de Estado, Nilo Peçanha - reconhecidamente um dos maiores defensores da fisiocracia fluminense (FERREIRA, 2010) - Paulo Alves assumia um discurso tecnocrático (PESSANHA, 1988), no qual modernização, urbanização e industrialização constituíam as palavraschave para o progresso de Niterói.

3 No entanto, após dez meses à frente da prefeitura, Paulo Alves renunciou ao cargo. Sofrendo forte oposição por parte da vereança niteroiense - um dos principais redutos de oposição ao nilismo no estado (FERREIRA, 1997) e destituído de maiores fidelizações partidárias ${ }^{4}$, Alves desistiu do seu projeto de transformar a capital fluminense em sinônimo de modernidade. No entanto, a receita para o progresso preconizada por Alves foi seguida por outros prefeitos e presidentes de Estado que independentemente da filiação partidária, buscaram através de um amplo programa de obras de remodelação, promoção de infraestrutura urbana, estímulo ao comércio e - alguns mais efusivamente à indústria, propiciar elementos para o progresso da cidade-capital.

4 Por mais que alguns autores apontem que o fomento à industrialização jamais figurou como uma alternativa econômica das elites para tentar subsistir aos efeitos da debàcle do café para a economia fluminense (FERREIRA, 1994), verificamos que em Niterói, esta opção jamais foi desconsiderada e é possível que em algumas ocasiões, possa até mesmo ter sido virtualmente estimulada. Afinal de contas, no que diz respeito às possibilidades agrícolas da cidade, restavam-lhe poucas opções. Desde 1890, as suas antigas freguesias rurais (São Gonçalo, Itaipu e Cordeiro), haviam sido desmembradas dando origem ao município de São Gonçalo ${ }^{5}$. A cidade ficou reduzida assim, a um território de $83,86 \mathrm{Km}^{2}$ em detrimento dos 245,42 $\mathrm{Km}^{2}$ de extensão existentes anteriormente (FORTE, 1941; PALMIER, 1940), sendo que cerca de 50\% desta nova área estava situada em área pantanosa, ou seja, era imprópria para a agricultura (MOTTA, 1997).

5 Lançando-se à interpretação dos dados coletados a partir do Censo Estadual de 1892, José Mattoso Maia Forte (1941) concluiu que a população urbana de Niterói contabilizava 36.056 pessoas, constituindo-se neste período, como maior população citadina do Estado ${ }^{6}$.

6 No entanto, para além do fato de ser “(...) um município totalmente desprovido de possibilidades em matéria de riqueza agrícola" (CARNEIRO apud PESSANHA, 1988, p. 59) Niterói, tornou-se um dos mais importantes polos de atração fabril do estado no decorrer das três primeiras décadas do século XX. Como justificativa para tal, acreditamos que contribuiu: $1^{\circ}$ ) a proximidade da cidade com o "(...) centro cultural, político e econômico" (FERREIRA, 1997, p. 79) que era a capital federal, Rio de Janeiro; $2^{\circ}$ ) o fato de Niterói ter desenvolvido certa infraestrutura urbana ao longo dos anos a fim de dar suporte ao seu estatuto de capital fluminense; $3^{\circ}$ ) o estímulo do governo estadual para instalação de 
indústrias no território fluminense, através da oferta de impostos mais baixos e/ ou isenção de impostos.

7 No que concerne a este primeiro aspecto, cabe destacar a importância de determinada produção historiográfica brasileira e estrangeira dos anos 1980 (GOMES \& FERREIRA, 1988), que buscou pensar a influência política e as especificidades econômicas da cidade do Rio de Janeiro, que desde o início do século XIX, destacou-se por sua intensa atividade comercial e protagonismo no debate político nacional. Tais análises foram fundamentais para superar o "modelo do complexo cafeeiro" que procurava pensar a indústria carioca e fluminense não como processos específicos, mas como simples repositórios do "paradigma paulista". Segundo este modelo, a industrialização brasileira durante a Primeira República esteve intimamente relacionada aos períodos de expansão/refluxo do café. Como São Paulo verificou altos índices de industrialização no momento de apogeu do café no estado, por conta da expansão de capitais e do mercado consumidor, o "modelo do complexo cafeeiro" adequa-se ao caso paulista, mas mostra-se inaplicável para a cidade e o estado do Rio de Janeiro, que verificou altos índices de industrialização justamente no momento de profunda crise do setor cafeeiro.

8 Enquanto Eulália Lobo (1992) chama a atenção para o fato de grande parte do capital investido na indústria carioca ter sido proveniente da acumulação comercial, Maria Antonieta Leopoldi (1986) argumenta que a crise cafeeira fluminense nas décadas de 1880 e 1890 estimulou o investimento em outras atividades produtivas no estado do Rio de Janeiro, principalmente a indústria. Para isso, certamente contribuiu uma conjuntura nacional favorável, manifestada através da expansão do crédito, da isenção de impostos e das facilidades de importação no período de euforia que antecedeu ao Encilhamento; e das tendências protecionistas do governo após deflagração da crise, evidenciadas pelas leis de auxílio e estímulo à indústria e as tarifas protecionistas. Stanley Stein (1979), que denominou este período de "anos dourados" da industrialização brasileira, chama a atenção também para a atuação política "de uma aristocracia de abastados industriais" ( Idem, p. 108) que buscavam cada vez mais influir, seja através de entidades classistas ou mandatos no legislativo, na política tarifária do governo.

9 Conduzindo a nossa análise especificamente para Niterói e para o estado do Rio de Janeiro, Marieta de Moraes Ferreira (1994) nos fornece importante contribuição. Para a autora, apesar do crescimento fabril visível verificado na província fluminense durante os primeiros anos da Primeira República, esta se deu apenas como um desdobramento da industrialização carioca e não como resultado de uma "opção industrialista" adotada pelas elites como alternativa para saída da crise agrícola:

É importante explicitar, entretanto, que essa expansão industrial fluminense se fez graças não à acumulação do capital local, mas com investimentos de empresários das indústrias cariocas. As características que assumiram as produções cafeeira e açucareira, agravadas pela crise do trabalho escravo, provocaram uma descapitalização desses setores e uma drenagem de seus capitais para os setores comerciais financeiros localizados na cidade do Rio de Janeiro, o que dificultava a realização de investimentos locais de maior porte. Assim, as principais empresas implantadas no Estado do Rio de Janeiro surgiram articuladas com atividades comerciais daquela cidade. Nesse contexto foram implantadas inúmeras fábricas e tiveram origem alguns núcleos industriais, tais como Niterói, Petrópolis, Magé e Campos (Idem, p. 52).

10 Além de ter sido desenvolvida a partir de investimentos oriundos do distrito federal, a autora destaca a pré-existência de ferrovias no estado, bem como a mão-de-obra 
disponível e que recebia salários mais baixos em relação aos trabalhadores da capital do país.

11 Corroborando em grande parte com as reflexões da autora, identificamos que tal qual a sua produção agrícola, a industrialização fluminense manteve uma forte relação de dependência do mercado carioca para escoamento da sua produção (GEIGER, 1956; CARVALHO, 1957). Esta eterna condição de hiterlândia (BERNARDES, 1971), que tanto desagradava à elite dirigente do estado e, sobretudo, da sua capital, não se deu, no entanto, sem que tentativas para transpô-la fossem colocadas em prática. Este aspecto, a nosso ver, encontra-se intimamente associado às tentativas modernizantes pelas quais a capital fluminense passou ao longo dos anos e nele se encontra o segundo ponto da nossa argumentação.

12 Desde que foi elevada à condição de Vila Real da Praia Grande, em 1819, Niterói passou por inúmeras intervenções urbanas que objetivavam conceder à Vila e posteriormente à capital da província, elementos que pudessem associá-la mais ao progresso e modernização, e menos ao atraso e ao provincianismo, atributos estes amplamente rechaçados pela elite local (CAMPOS, 2004) e que representavam sérios obstáculos para o desenvolvimento da sua tão almejada capitalidade. $\mathrm{E}$ se isso não consiste propriamente em uma novidade quando pensamos em planejamentos para áreas urbanas, em Niterói, "a modernização" configurava uma necessidade premente para que a cidade pudesse permanecer como capital do estado do Rio de Janeiro, estatuto este sempre posto em xeque, sobretudo por lideranças políticas de outras cidades do estado7.

Por maior que seja, pois, o espaço fluminense, o estado do Rio é sempre aquele estado que se acha fronteiro à grande metrópole (...) 0 mineiro pode ter seus hábitos e o carioca os respeita, assim como os outros estados. Mas o fluminense não pode ter. Se é certo que ele não evolui com a precipitação do carioca, porque não será submetido às mesmas influências, a verdade é que a proximidade da capital sempre exerce essa influência demolidora, que não lhe permite criar uma personalidade própria, um caráter étnico, moral ou social que o tipifique (MEDEIROS apud FERREIRA, 1997, p. 80).

14 Esta proximidade de Niterói com o Rio de Janeiro possibilitava um maior contato com um modelo de "urbe" que se desejava seguir e ao mesmo tempo, impelia a capital fluminense a impor a si o seu próprio paradigma de cidade, numa tentativa forçosa de adquirir não só mais autonomia frente à capital federal, mas de assumir de vez seu lugar como capital do estado. É claro que tal esforço esbarrava em uma série de obstáculos, alguns até muito difíceis de transpor, como a relação de dependência econômica que a cidade de Niterói e o estado do Rio de Janeiro como um todo tinham em relação a capital. Porém, mesmo com todos os limites e contradições, observamos que Niterói buscou continuamente reinventar seu mito fundacional de capital do estado (HOLSTON, 1993), investindo pesadamente no ideário poderoso - mas nem sempre convincente, de progresso e modernização. Neste sentido, ressaltamos a particular importância das intervenções urbanas subvencionadas pelo poder público neste processo, bem como as tentativas de superar a "falta de identidade econômica crônica" (PESSANHA, 1988, p. 60) da cidade, possibilitando o investimento em outras atividades produtivas diferentes da agricultura, em particular, no setor fabril.

Pensando o espaço urbano como um elemento central do modo de produção capitalista, Henri Lefebvre analisa como a "produção do espaço" produz relações sociais ao mesmo 
tempo em que são produzidas por elas. Neste sentido, a industrialização - comumente dimensionada como "produtora" do espaço urbano - encontra-se na realidade, inserida em um processo dialético no qual ao mesmo tempo em que "cria" o espaço urbano, é "criada" por ele (LEFEBVRE, 2004, p. 38). Nas palavras do autor: “(...) industrialização e urbanização, crescimento e desenvolvimento, produção econômica e vida social. Os dois 'aspectos' deste processo, inseparáveis, têm uma unidade, e no entanto o processo é conflitante" (LEFEBVRE, 2001, p. 9).

Conduzindo as reflexões de Lefebvre para o nosso estudo de caso, percebemos o quanto a industrialização de Niterói, ao contrário de ter se configurado como um mero acaso ou apenas como um reflexo da industrialização carioca, esteve intimamente relacionada à urbanização e ambas, aos discursos de modernização que permearam a trajetória da cidade. Neste sentido, por mais que não nos seja possível atribuir certa "convicção industrialista" às lideranças políticas que atuavam na capital fluminense, visto que a maior parte delas estava associada ao nilismo ou ao sodrelismo - ambas correntes políticas comprometidas com o agrarismo no estado - não podemos perder de vista que as possibilidades agrícolas de Niterói eram irrisórias e por isso, a opção industrial figurou como uma alternativa econômica para a cidade, tal como podemos perceber nas palavras do liberal convicto e completamente avesso a qualquer tipo de intervenção do estado na economia, Otávio Carneiro ${ }^{8}$ :

Nictheroy é, como vos fez notar a um anno, um município totalmente desprovido de possibilidades em matéria de riqueza agrícola. As bases econômicas da sua vida teem de ser outras e Nictheroy só as poderá encontrar constituindo-se de um lado em cidade industrial, em entreposto comercial de uma parte do interior do Estado e d'outro lado em cidade residência (CARNEIRO apud PESSANHA, 1988, p. 59).

A possibilidade de pagar impostos mais baratos ou até mesmo isentar-se do pagamento destes, também se apresentou como um elemento de atração para os empreendedores industriais que desejavam instalar os seus negócios na cidade. Consultando os Relatórios dos Presidentes de Estado, identificamos vários decretos, leis e deliberações estaduais que previam a concessão de favores e isenção de impostos para as fábricas instaladas no estado e particularmente na cidade de Niterói'. Isso indica, a nosso ver, que se a "opção industrialista" não foi objetivamente estimulada pelas elites dirigentes, como atestou Marieta de Moraes Ferreira (1994), ela não foi também completamente rechaçada pelas mesmas.

As primeiras fábricas chegaram à cidade, porém, ainda no período imperial. Na capital da Província, além da fábrica de óleos vegetais (1841), de iluminação a gás (1847), química (1851), de cal (1853) - todas estas estabelecidas a partir de vantagens legais e tributárias concedidas pelo governo provincial (HONORATO \& BEAUCLAIR, 1997) - destacamos aqui a relevância do estaleiro Mauá da Ponta D'Areia, ${ }^{10}$ como o maior empreendimento da localidade neste "primeiro surto industrial" da cidade.

São várias as razões apontadas na literatura especializada para a efemeridade destes primeiros empreendimentos industriais. Para Maria Antonieta Leopoldi (1986), por exemplo, as tarifas oscilantes, a falta de mão-de-obra especializada e a limitação da expansão do mercado interno por conta da escravidão, prejudicaram o desenvolvimento da atividade manufatureira neste período. Já para Stanley Stein (1979), as dificuldades enfrentadas pelos empreendedores fabris para obtenção de crédito e as garantias exigidas pelo governo imperial às sociedades anônimas, impôs sérias limitações à indústria até a década de 1890. 
20 No último decênio do século XIX, já na República, podemos vislumbrar vários novos estabelecimentos fabris na cidade. Apesar da prevalência das indústrias de consumo, podemos identificar a presença de algumas indústrias de transformação, tais como metalúrgicas, indústrias químicas e têxteis, indústrias relacionadas à construção civil (ladrilhos, olarias, etc.), bem como a existência de estaleiros. As reformas urbanas que a cidade de Niterói passou durante a gestão do então Presidente de Estado, Nilo Peçanha (1903-1906), com destaque à substituição do sistema de iluminação a gás pelo o de luz elétrica e a instalação de novas linhas de bondes elétricos (FERREIRA, 1994), corroboraram sem dúvida, para maiores investimentos da ainda incipiente indústria na região.

21 Entre as fábricas instaladas na cidade que possuíam maior capacidade de produção e que empregava mais de 100 trabalhadores, podemos citar aqui: a Fábrica de Fumos de J. F. Corrêa e Cia. ou "Marca Veado"11, a Cia. Manufatora Fluminense de Tecidos (1893), Fábricas de Fósforos Antônio Migliora ou "Marca Olho" (1893), a fábrica têxtil Cia. Fabril São Joaquim (1893), Fábrica de Fósforos Brazil (1895), a Fábrica de Fósforos Brilhante (1903), e Cia. De Fósforos Fiat Lux (1904) ${ }^{12}$. A maior quantidade de empresas, porém, se caracterizava por pequenas fábricas voltadas para o consumo, com destaque para as usinas de açúcar, olarias e fábricas de fumo que já tinham presença significativa na cidade desde o período imperial e que se mantiveram ainda numerosas na República (FORTE, 1941; WEHRS, 1984).

22 A localização fabril era bem dispersa, concentrando-se principalmente no centro da cidade (apenas pequenas fábricas e até o início do século XX), em áreas contíguas ao centro da cidade (bairros da Ponta d'Areia, Ilha da Conceição, Gragoatá) e principalmente nos bairros da zona norte (Barreto, São Lourenço, Santana e Fonseca).

23 No que concerne à construção naval, podemos dizer que este setor teve uma participação significativa na conformação da paisagem industrial da cidade, destacando-se tanto por sua capacidade produtiva, quanto por seus altos índices de empregabilidade. Tratando-se de um tipo de indústria antigo, que remonta ao período colonial, os estaleiros chegaram à cidade de Niterói ainda no Império, graças às subvenções governamentais que visavam incrementar a frota naval brasileira destinada ao transporte de pessoas e de mercadorias (PESSANHA, 1986). Tendo uma parcela considerável do seu território cercado pela Baía de Guanabara, onde na parte norte “(...) penetra um mar profundo e calmo" (GEIGER, 1956, p. 497) e estando situada bem próxima ao Rio de Janeiro, a capital da província foi se tornando um local privilegiado para este tipo de empreendimento.

24 Em fins do século XIX e início do século XX, já sobre égide do regime republicano, várias companhias de navegação se instalaram na cidade, a saber: a Cia. Nacional de Navegação Costeira Lage \& Irmãos, localizada nas Ilhas do Viana e da Velha e que empregava cerca de 900 trabalhadores; a C. H. Walker \& Cia., localizada na Ponta d'Areia e que contava com 400 operários trabalhando em suas instalações; a Cia. Novo Lloyd situada na Ilha do Macanguê Pequeno e a Wilson \& Sons localizada na Ilha da Conceição, ambas com 200 trabalhadores; a Carlos Wigg, no Mocanguê Grande com 50 trabalhadores e a Almeida Neves, na Ilha da Conceição, com 30 (BIBLIOTECA ESTADUAL DE NITERÓI, 1904).

Segundo Alcides Goularti Filho (2011), a defasagem técnica da produção nacional - que tinha como base a madeira enquanto a produção internacional já usava o ferro e o aço em larga escala - levou à incorporação de pequenos estaleiros por outros de maior porte. Em 1890, por exemplo, a estatal Cia. Lloyd Brasileiro ${ }^{13}$, localizada em Niterói, incorporou a 
Companhia Brasileira de Navegação a Vapor, a Companhia Nacional de Navegação a Vapor e a Companhia Espírito Santo e Caravelas e se tornou, em fins da década de 1920, a mais importante companhia de navegação do país contando com área de $133.000 \mathrm{~m}^{2}, 2.141$ trabalhadores a seu serviço e 98 navios em sua frota mercante. 0 segundo lugar cabia a Cia. Nacional de Navegação Costeira pertencente às Organizações Lage, que possuía $226.000 \mathrm{~m}^{2}$ de área construída (a maior do país), 1.800 trabalhadores e 21 navios em sua frota mercante. A Cia. de Comércio e Navegação fundada no ano de 1905, nas antigas instalações do estaleiro Mauá, na Ponta d'Areia, ocupava o terceiro lugar no ranking dos mais importantes estaleiros brasileiros, ocupando uma área de $32.040 \mathrm{~m}^{2}$, com 150 trabalhadores e frota de 20 navios.

Considerado um setor estratégico para a economia nacional, visto que o desenvolvimento do transporte marítimo era essencial para a exportação de gêneros primários, os estaleiros (mesmo os privados), recebiam subvenções governamentais significativas para o seu desenvolvimento. Com base na Constituição de 1891, que previa a proteção ao transporte marítimo de cabotagem, o governo auxiliava as companhias de navegação que viessem a se encontrar em dificuldades financeiras (Idem, p. 331), como foi o caso das Organizações Lage, que por duas ocasiões foi socorrida pelo Banco do Brasil para saldar os salários atrasados dos operários em greve, até ser encampada pelo governo em 1941 (PESSANHA, 1986).

A presença dos estaleiros na cidade de Niterói acabou estimulando o desenvolvimento de outras atividades fabris que funcionavam em complementaridade às demandas da indústria naval. Neste sentido, é possível que algumas serralherias, fábricas de tintas, de pregos, de tecidos de algodão, depósitos de carvão, fundições e metalúrgicas, verificadas na cidade principalmente após a segunda década do século XX, tenham sido criadas na tentativa de atender a este mercado. Em Niterói, as Organizações Lage" fundaram a Fábrica de Tecidos Maruí para suprir as necessidades da Cia. de Navegação Costeira, além de possuir um depósito de carvão em pedra (FORTE, 1941).

No município vizinho, São Gonçalo, vislumbramos um forte desenvolvimento de "indústrias de base", com destaque para a Fundição Hime \& Cia (metalúrgica) e a Cia. Brasileira de Usinas Metalúrgicas, ambas localizadas no bairro de Neves (área conurbada ao bairro niteroiense do Barreto). Ainda que não possamos atribuir à industrialização gonçalense apenas uma condição de complementaridade à indústria niteroiense, já que o processo fabril deste município foi marcado por singularidades (LESSA, 2009), é possível identificarmos inúmeras confluências entre a "região industrial e operária" destas duas cidades, aspecto este que mais adiante esmiuçaremos.

Os setores de transportes e da construção civil também merecem ser destacados como elementos importantes na configuração espacial, social e econômica da cidade. Sobre o primeiro, ressaltamos aqui a importância da Cia. Cantareira e Viação Fluminense (CCVF) ${ }^{14}$, a Estrada de Ferro da Leopoldina ${ }^{15}$ e do Serviço de Viação de Niterói e São Gonçalo $(\mathrm{SERVE})^{16}$, que além de cumprirem um papel destacado no que diz respeito à geração de empregos e a circulação de pessoas e mercadorias, concentraram duas das mais importantes categorias sindicais da cidade.

No que concerne à construção civil, já assinalamos como as obras de remodelação pelas quais a cidade de Niterói passou ao longo dos anos, foram importantes para a reafirmação do seu estatuto de capital fluminense. No período que antecedeu aos anos 1930, identificamos o governo de Feliciano Sodré como um momento em que esta relação urbanização-modernização atingiu particular importância. 
31 Tanto quando esteve à frente do executivo municipal (1910-1914), quanto estadual (1923-1927), o governo de Sodré foi marcado por forte intervencionismo. Segundo Mary Pessanha (1988), tal postura foi articulada como uma tentativa de arrefecer as hostes nilistas e forjar o seu enraizamento político no estado. Ainda que não seja nosso interesse aprofundar estas disputas políticas protagonizadas por Feliciano Sodré e Nilo Peçanha, interessa-nos chamar a atenção aqui para a "intervenção estatal no urbano" (Idem, pp. 89-94) preconizada por Sodré, que, através dos seus programas de remodelação e do seu projeto para a construção de um porto em Niterói, incorporou um forte discurso “autonomista”, bem como arregimentou um grande número de trabalhadores.

Por ocasião de seu mandato como prefeito, Sodré mandou erigir pequenas fábricas de ladrilhos, cimento, tijolos, marcenarias, carpintarias, etc., a fim de fornecer o material necessário para as obras de reforma e infraestrutura urbana. Este intervencionismo, bastante atípico para um período em que se primava pelo liberalismo, era justificado pela possibilidade de se fazer uma “(...) grande economia para os cofres municipaes" (BIBLIOTECA ESTADUAL DE NITERÓI, 1913), além de gerar muitos empregos - ainda que este último aspecto não fosse objeto de grandes considerações nos relatórios.

A construção do porto - planejada por Sodré quando era prefeito, mas apenas levada a cabo por ele quando se tornou Presidente de Estado - foi objeto de muita polêmica (PESSANHA, 1988; CRUZ, 1999; COSTA, 2010). Concebido por seus defensores como uma "promessa de autonomia" para a cidade, o porto de Niterói nascia junto com a missão de desvencilhar a capital fluminense de sua condição de hiterlândia e por extensão, de sua situação de dependência política em relação à capital federal. Apesar de ter reunido um grande volume de capital e um vasto programa de obras, o porto não chegou a funcionar plenamente na Primeira República, sendo o seu projeto novamente retomado por Amaral Peixoto, em 1941, quando a sua administração passou a ficar a encargo do estado ${ }^{17}$.

Motivados pelas possibilidades de ocupação diferentes do trabalho na lavoura, milhares de trabalhadores rurais migraram para Niterói. Eles vinham de Minas Gerais, Espírito Santo ${ }^{18}$ e, sobretudo, do interior do estado do Rio: "Porque na época não existia trabalho assim... quem vivia na roça, tinha que trabalhar na roça. Aí o pessoal sai da roça e corre pra cidade" (MARTINS, 2009); "A maioria dos companheiros era daqui e de outros municípios, Bom Jesus, outro de São Fidelis, outro de Macaé (...) aquele êxodo rural que veio pra formar as favelas" (SOUZA, 1996). Buscando empregar-se nas fábricas, comércio ou construção civil, estes trabalhadores tiveram um papel decisivo no desenvolvimento da economia local e na configuração da classe trabalhadora da cidade.

Esta tendência migratória do interior do estado do Rio para capital, possível de ser identificada desde pelo menos a segunda metade do século XIX, se acelerou ainda mais com o passar dos anos. Entre os anos 1920 e 1940, por exemplo, a população residente na capital fluminense quase duplicou, enquanto 29 dos 50 municípios do estado registraram decréscimo em sua população (KELLER, 1953). Ainda que não nos seja possível afirmar que exista uma correlação direta entre estes números, alguns estudos realizados por pesquisadores do IBGE nos indicam que parte deste desequilíbrio se justificava pelo êxodo da população rural para áreas mais urbanizadas e industrializadas do estado (ver tabela nำ1) ${ }^{19}$

Niterói, centro político-administrativo do estado, tem uma tendência natural a aumentar a população pela atração que exerce como capital, além de que, seus estabelecimentos industriais constituem atração pelos seus salários compensadores, contribuindo assim, para o aumento da população urbana. Outro fator importante a 
se considerar no aumento dos habitantes urbanos de Niterói é o fato de ter aí fixado residência grande número de pessoas que trabalham no Rio de Janeiro, funcionando a capital do estado, nesse sentido, quase como subúrbio da Capital Federal, o mesmo fato verificado para as vizinhas cidades de Nova Iguaçu, Caxias e Nilópolis (KELLER, 1953, p. 165).

Se por um lado, a opção por trabalhar no Distrito Federal e residir em Niterói, justificavase ante a possibilidade de adquirir terrenos a preços mais baratos e ter um custo de vida inferior em relação ao da capital federal (FORTE, 1941); por outro, a capital fluminense também oferecia opções de trabalho no comércio, no setor de serviços e na indústria, conforme já abordamos. No período posterior aos anos 1930, a cidade teve um incremento de 34 novos estabelecimentos industriais no intervalo entre 1930-1940; entre 1940-1950 foram mais de 100. Em 1953, Niterói já registrava 191 indústrias e uma população operária de $11.028^{20}$ (GEIGER, 1957, p. 49).

Outros fatores, tais como: a alta concentração fundiária, os salários irrisórios pagos ao trabalhador do campo e a quase total ausência de serviços públicos disponibilizados à população rural, também acabaram estimulando estas correntes migratórias do interior fluminense para as áreas mais urbanizadas do estado (MENDONÇA \& SANTOS, 1986; MOTTA, 1997). Ainda que não possamos desprezar os números referentes à população originária de outros estados do país, bem como de imigrantes europeus presentes em Niterói, dados censitários nos indicam que a origem fluminense constituía maioria esmagadora da população da cidade. De acordo com o Censo de 1950, dos 186.309 habitantes presentes no município até aquela data, 144.154 pessoas eram originárias do estado do Rio ${ }^{21}$.

Tabela 1: Dinâmica populacional nos municípios do estado do Rio de Janeiro (1920-1940)

\begin{tabular}{|cccc|}
\hline Municípios & População em 1920 & População em 1940 & Saldo populacional \\
\hline Niterói & 86.238 & 142.407 & +56.169 \\
\hline Nova Iguaçu $^{*}$ & 33.396 & 140.606 & +107.021 \\
\hline São Gonçalo & 47.019 & 89.528 & +42.509 \\
\hline Petrópolis & 67.574 & 84.875 & +17.301 \\
\hline Capivari & 25.406 & 14.120 & -11.286 \\
\hline Duas Barras & 19.391 & 10.158 & -9.233 \\
\hline Cantagalo & 37.112 & 28.467 & -8.645 \\
\hline Parati & 13.544 & 9.673 & -3.871 \\
\hline
\end{tabular}

Fonte: KELLER, Elza Coelho de Souza. Crescimento da população do estado do Rio de Janeiro. Revista Brasileira de Geografia. Rio de Janeiro: IBGE, jan-mar 1953. Tabela elaborada pela autora. *Neste período, Duque de Caxias, São João de Meriti e Nilópolis eram distritos do município de Nova Iguaçu.

Seguindo a tendência verificada por Maurício de Abreu (2006) sobre a ocupação urbana da cidade do Rio de Janeiro, Niterói também se caracterizou pela ingerência do poder público no controle da ocupação das áreas centrais, dotadas de maior infraestrutura e no processo de transferência compulsória da população mais pobre para outras áreas mais periféricas. Tal qual ocorreu na capital federal em fins do séc. XIX e início do séc. XX, o argumento higienista constava na ordem do dia da vereança niteroiense que buscava legitimar 
cientificamente as suas intervenções no espaço urbano (CAMPOS, 2004). Porém, é importante assinalar que em termos de extensão territorial, o antigo Distrito Federal era quase dez vezes maior do que cidade de Niterói ${ }^{22}$. Sendo assim, a separação entre os bairros abastados e de classe média e os bairros operários da capital fluminense se dava pela mais pela presença/ ausência de infraestrutura urbana do que propriamente pela distância.

Os bairros que já registravam grande ocupação industrial desde o século XIX, tais como: Barreto, São Lourenço, Santana, Ponta d'Areia e Ilha da Conceição, começaram a receber grandes contingentes de trabalhadores que, em terra firme ou nas encostas dos morros, passaram a erigir as suas residências dando nova forma e conteúdo à cidade. Estes e mais outros bairros principalmente localizados na zona norte de Niterói (Engenhoca, Caramujo, Fonseca, Tenente Jardim, Viçoso Jardim, Baldeador, Santa Bárbara e Cubango) ${ }^{23}$ , também reconhecidos como locais de grande concentração proletária passaram a compor o que estamos denominando aqui de "região industrial e operária da cidade" (ver mapa nำ)

O conceito de região, tão polissêmico na compreensão dos geógrafos (HAESBAERT, 2010) tem sido largamente revisitado por estes nos últimos anos e vem resultando em abordagens inovadoras e bastante profícuas para pesquisadores de diferentes campos do conhecimento. Concebida não apenas como um "fato concreto", seccionada a partir de critérios "naturais", "econômicos", "políticos", "sociais" e nem tampouco como uma metáfora "inventada" para demarcar processos culturais e identitários, a região é encarada como uma articulação entre a materialidade do espaço e suas representações, ou, nas palavras de Rogério Haesbaert, como um arte-fato:

A região vista como um artefato é concebida no sentido de romper com a dualidade que muitos advogam entre posturas mais estritamente realistas e idealistas, "constructo" ao mesmo tempo de natureza ideal-simbólica (seja no sentido de uma construção teórica, enquanto representação do espaço, seja de uma construção identitária a partir do espaço vivido) e material-fundacional (nas práticas econômico-políticas com que os grupos ou classes sociais constroem seu espaço de forma desigual/ diferenciada). "Arte-fato" (com hífem) também permite indicar que o regional é abordado ao mesmo tempo como criação, autofazer-se ("arte") e como construção já produzida e articulada (Idem, pp. 109-110).

41 Tratando-se de uma região que foi conformada a partir da ocupação fabril, seguida da migração dos trabalhadores para determinadas localidades da cidade menos guarnecidas de infraestrutura urbana, a "região industrial e operária de Niterói" foi constituída a partir de condicionantes econômicos e da ingerência direta do poder público. Por outro lado, observamos que as "redes" tecidas pelos trabalhadores em seu ambiente de trabalho e moradia, nos seus espaços de lazer, convivência e militância sindical, tiveram lugar decisivo na constituição desta região. 


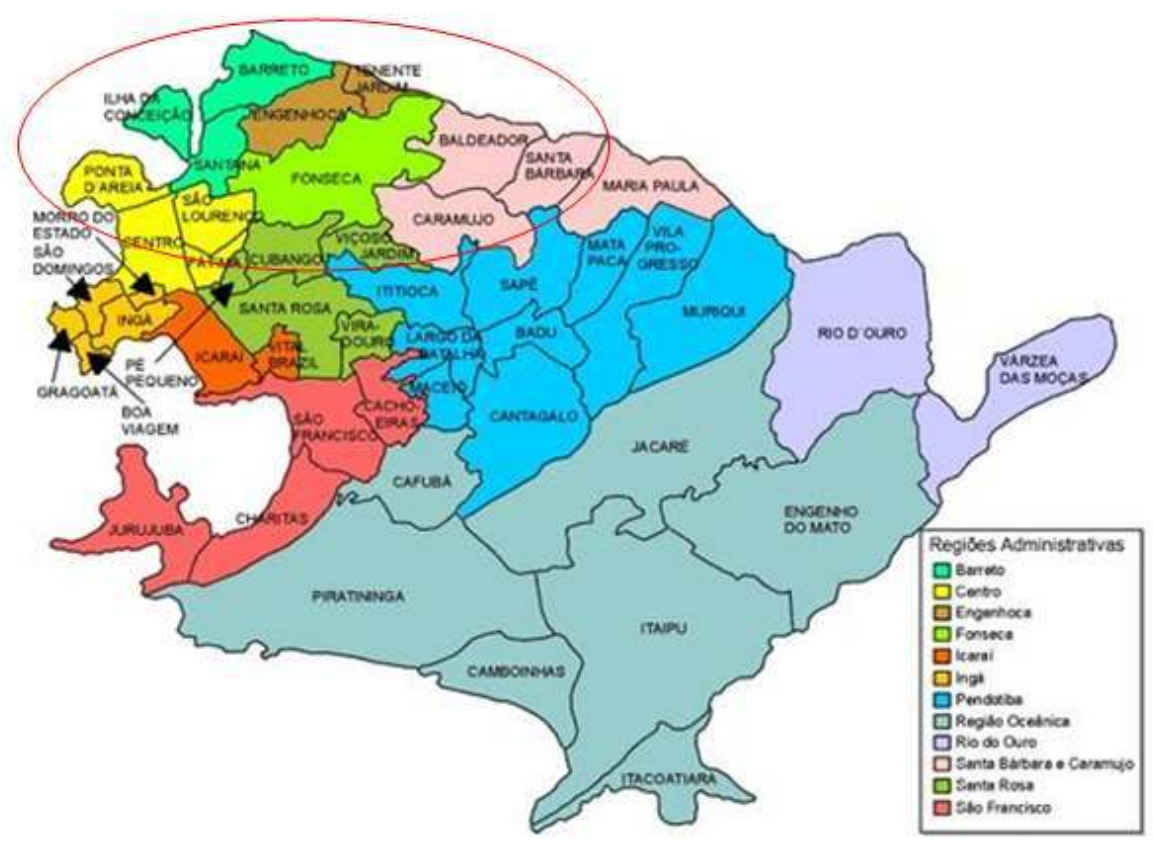

Fonte: Disponível em: http://www.webbusca.com.br/pagam/niteroi/mapa_niteroi.jpg

Buscando aprofundar alguns aspectos suscitados historiografia social do trabalho já clássica, tais como os de Edward P. Thompson e Eric Hobsbawm alguns pesquisadores vêm buscando uma maior interlocução entre a história operária e a história urbana, defendendo assim uma maior "sensibilidade espacial" aos estudos voltados para a classe trabalhadora (OYON, 2002; SAVAGE, 2004).

Corroborando com estas análises, consideramos que para além dos locais de trabalho ou sindicatos, a formação de classe também possui uma dinâmica espacial que não pode ser desconsiderada. Seja em grandes aglomerações urbanas ou em pequenas localidades, atentar para a esfera espacial significa aproximar-se ainda mais dos aspectos cotidianos, das múltiplas experiências e das especificidades que caracterizam um grupo, uma dada formação de classe.

4 É claro que não se trata de substituir o "global" pelo "local" e nem tampouco supervalorizar a esfera espacial, em detrimento das questões de classe. Concordamos com Mike Savage (2004) quando este afirma que discutir a proeminência do global sobre o local ou vice e versa mostra-se irrelevante, quando o que se busca é justamente considerar a interconexão entre eles, “(.) as suas complexas interligações entre níveis espaciais distintos” (p. 40). E essa correlação entre diferentes escalas espaciais não ocorre sem que conflitos e descontinuidades se apresentem. Afinal de contas, a estrutura do espaço representa “(...) um componente dialeticamente definido das relações de produção gerais, relações estas que são simultaneamente sociais e espaciais", como afirmou o geógrafo Edward Soja (1993, p. 99) ao desenvolver suas ideias em torno da "dialética sócio-espacial".

Para Savage, é possível pensarmos no caráter sociocultural e político da formação de classe se incluirmos além do conceito de espaço, o conceito de rede em nossa análise. Para este autor, as redes densas correspondem aos aspectos relacionados ao habitus; já as redes 
de largo alcance estão associadas aos aspectos políticos/ ideológicos que permitem associar pessoas para além do contato face a face. Sendo assim, podemos considerar esta ideia de "dinâmica dual das redes" desenvolvida por Savage (2011) bem interessante para pensar "a região industrial e operária de Niterói".

o principal benefício de adotar uma perspectiva de rede é que ela nos permite ir além da ideia de classes como sendo "formadas" de algum modo definitivo. Antes, ela coloca a ênfase na natureza fluida e dinâmica da formação de classe em que dois processos diversos constantemente ameaçam cortar pela base a existência de classes como coletividades sociais estáveis. Isso pode nos ajudar a iluminar os modos verdadeiramente reais em que classe pode importar historicamente em situações específicas, assim como reconhecer que classes não são coisas que necessariamente têm alguma pertinência para a análise. É, portanto, claramente possível usar o conceito de formação de classe de forma que ajude a explorar a complexidade de situações históricas, em lugar de reduzi-las a uma fórmula simples (Idem, p. 32-33).

Sendo assim, apesar da proeminência da zona norte em nossa análise, é importante não perder de vista como determinadas "redes - amplas e densas" foram se constituindo para além da região. Isso nos parece particularmente importante quando observamos as múltiplas conexões existentes entre a "região industrial e operária" de Niterói e São Gonçalo, sobretudo nas áreas contíguas à capital fluminense (os bairros gonçalenses de Neves e Venda da Cruz), e de ambas com a cidade do Rio de Janeiro - que além da centralidade política e econômica que exercia, constituía o local de origem de muitos trabalhadores.

Tendo ocupado o posto de capital do estado do Rio de Janeiro até a fusão deste estado com antiga Guanabara em 1975, Niterói buscou investir em atividades produtivas particularmente no setor fabril - a fim conquistar a sua autonomia e sair de vez do lugar de hiterlândia fluminense. Mesmo com todas as dificuldades em suplantar essa condição de subalternidade - jamais superados ante a capital federal - a capital fluminense serviu de polo de atração para milhares de trabalhadores e trabalhadoras que migraram para a cidade em busca de novas oportunidades de vida e trabalho. Essa concentração operária oriunda da atividade fabril, somada à sua condição de capital do estado, atraiu para a cidade uma grande quantidade de comitês municipais e estaduais de partidos políticos, além de sindicatos de âmbito estadual e sedes das federações de trabalhadores de diferentes categorias. Desta maneira, mais do que sentir de perto o "calor" dos principais acontecimentos políticos que ocorriam no país naquele período - em virtude da sua proximidade da capital federal - Niterói mostrou-se também um "termômetro" das lutas que se processavam cenário nacional no período pré-1964.

\section{BIBLIOGRAFIA}

ABREU, Mauricio. Evolução Urbana do Rio de Janeiro. Rio de Janeiro: IPP, 2006.

BERNARDES, Lysia M. C. Considerações sobre a região do Rio de Janeiro. Revista Brasileira de Geografia. Vol. 33, no 4, 1971 
BIBLIOTECA NACIONAL. Almanak Laemmert, 1906, 1910, 1915, 1921, 1922-1923, 1925, 1930, 1935 e 1940 - 4ํvolume - Estados do Sul.

CAMPOS, Maristela Chicharo de. O governo da cidade: elites locais e urbanização de Niterói (1835-1890). UFF: Niterói, 2004. Tese de doutorado.

CARONE, Edgard. o Centro Industrial do Rio de Janeiro e a sua importante participação na economia nacional (1827-1977). Rio de Janeiro: Editora Cátedra, 1978.

CARVALHO, Maria da Gloria de. Causas geográficas do desenvolvimento de olarias na Baixada da Guanabara. Anuário Geográfico do estado do Rio de Janeiro. Rio de Janeiro, oㅡ 10, 1957.

CD-ROM. UFF/ NDC/ CMF/ BN (org.). Relatório de Prefeitos de Niterói (1904-1977).

COSTA, Milena Sampaio da. Diferentes reflexões sobre desafios e perspectivas para as áreas portuárias do Rio de Janeiro e Niterói. Anais. I ENANPARQ. Rio de Janeiro: 2010.

CRUZ, Maria Cecília Velasco e. “O porto do Rio de Janeiro no século XIX: Uma realidade de muitas faces”. Revista Tempo. Niterói: º 8, agosto de 1999.

FERREIRA, Marieta de Moraes (coord.); Mônica Kornis (et. al.). A República da Velha Província. Rio de Janeiro: Rio Fundo, 1989.

. A velha província fluminense: crises e alternativas. p. 27. In: CÔRTE, Andrea Têlo (org). Anais do Colóquio Nilo Peçanha e o Rio de Janeiro no cenário da federação. Niterói: MHAERJ, 2010.

. Em busca da Idade do Ouro: as elites políticas fluminenses na Primeira República. Rio de Janeiro: Editora UFRJ, 1994.

. "Niterói Poder". In: MARTINS, Ismênia de Lima \& Paulo Knauss (org). Cidade Múltipla - temas para a história de Niterói. Niterói: Niterói Livros, 1997.

FILHO, Alcides Goularti. História econômica da indústria naval no Brasil: formação de aglomerado e performance inovativa. Revista Economia. Brasília: ANPEC, Vol. 12, nº 2, maio-agosto de 2011.

FORTE, José Matoso Maia. O Município de Niterói: corografia, história e estatística. Rio de Janeiro: Jornal do Commercio, 1941.

GEIGER, Pedro Pinchas. Urbanização e industrialização na orla oriental da Baía de Guanabara. Anuário Geográfico do estado do Rio de Janeiro. Rio de Janeiro, ํํ 9, 1956.

GUIMARÃES, Maria Rita da Silva. Estudo da população ativa fluminense e sua utilização nas zonas econômicas do estado. Revista Brasileira de Geografia. Rio de Janeiro: IBGE, out.-dez. 1957.

GOMES, Ângela de castro e Marieta de Moraes Ferreira. Industrialização e classe trabalhadora no Rio de Janeiro: novas perspectivas de análise. Rio de Janeiro: Centro de Pesquisa e Documentação de História Contemporânea do Brasil, 1988.

HAESBAERT, Rogério. Regional-global: dilemas da Região e da Regionalização na Geografia Contemporânea. Rio de Janeiro: Bertrand Brasil, 2010.

IBGE. Censo Demográfico de 1950. Rio de Janeiro, 1951.

IBGE. Documentação histórica dos distritos e municípios do estado do Rio de Janeiro. Anuário Geográfico do Estado do Rio de Janeiro. ㄲo 11, 1958.

KELLER, Elza Coelho de Souza. Crescimento da população do estado do Rio de Janeiro. Revista Brasileira de Geografia. Rio de Janeiro: IBGE, jan-mar 1953. 
LEOPOLDI, Maria Antonieta. Crescimento industrial, políticas governamentais e organização da burguesia: Rio de Janeiro, de 1844 a 1914. Revista Rio de Janeiro. Vol. 1, № 3. Niterói, maio-agosto de 1986, pp. 53-73.

LESSA, José Luís Honorato. A paisagem revelada: natureza e concentração industrial em São Gonçalo (RJ): crise ou reestruturação da indústria local?. São Gonçalo: UERJ/ FFP, 2009. Dissertação de mestrado.

LEFEBVRE, Henri. A Revolução Urbana. Belo Horizonte: Editora UFMG, 2004. p. 38. . 0 direito à cidade. São Paulo: Centauro, 2001. p 9.

LLOYD'S GREATER BRITAIN PUBLISHING COMPANY LTDA, 1913. Disponível em: http:// www.novomilenio.inf.br/santos/h0300g00.htm

LOBO, Eulália Maria Lahmeyer. Estado, movimento operário e condições de vida: Rio de Janeiro (1930-1970). pp. 1-19. In: LOBO, Eulália Maria Lahmeyer (coord). Rio de janeiro operário: natureza de estado, a conjuntura econômica, condições de vida e consciência de classe (1930-1970). Rio de Janeiro: Access, 1992.

MARTINS, Orédio Fernandes. Entrevista concedida à autora. Niterói: 18 jun 2009.

MATTOS, Marcelo Badaró. Escravizados e livres: experiências comuns na formação da classe trabalhadora carioca. Rio de Janeiro: Bom Texto, 2008. p. 16.

MENDONÇA, Sônia Regina de. O Ruralismo Fluminense na Primeira República. Revista Rio de Janeiro. Ano 1, nº 2, jul./ dez. 1993

MOMESSO, Beatriz Piva. Indústria e trabalho no século XIX: o Estabelecimento de Fundição e Máquinas da Ponta d'Areia. Niterói: UFF, 2007. Dissertação de mestrado.

MOTTA, Márcia Maria Menendes. Niterói Rural: elite de ontem e os arrendatários de outrora (1808-1888). In: MARTINS, Ismênia de Lima \& Paulo Knauss (org). Cidade Múltipla - temas para a história de Niterói. Niterói: Niterói Livros, 1997.

NUNES, Edson. A Revolta das Barcas: populismo, violência e conflito político. Rio de Janeiro: Garamond, 2000.

OYON, José Luis. "Historia urbana y historia obrera: reflexiones sobre la vida obrera y su inscripción em la espacio urbani, 1900-1950.” Perspectivas Urbanas, ํㅡㄹ 2002.

PALMIER, Luiz. São Gonçalo cinquentenário. Rio de Janeiro: IBGE, 1940.

PESSANHA, Elina. Vida operária e política: os trabalhadores da construção naval de Niterói. São Paulo: UPS, 1986. Tese de doutorado

PESSANHA, Mary Cristina. Porto de Nictheroy: uma promessa de autonomia. Rio de Janeiro: IPURR/ UFRJ, 1988. Dissertação de mestrado.

SANTOS, Ana Maria e Sônia Regina de Mendonça. Intervenção estatal e diversificação agrícola do Estado do Rio de Janeiro. Revista do Rio de Janeiro. vol. 1, no 2, Niterói: jan-abr. 1986.

SAVAGE, Mike. “Classe e História do Trabalho”. In: BATALHA, Cláudio H. M., SILVA, Fernando Teixeira da, FORTES, Alexandre. Culturas de classe. - identidade e diversidade na formação do operariado. Campinas: UNICAMP, 2004.

“Espaço, redes e formação de classe". Revista Mundos do Trabalho, vol. 3, nํ5, janjun. 2011. 
SOUZA, Irineu José de. Entrevista concedida ao Laboratório de História Oral (LABHOI) da UFF. Projeto: Niterói: os operários navais. Entrevistadores: Fernando Manoel Perez Cruz e Robson Silva. Data: 18/12/1996.

SOUZA, José Antonio Soares de. Da Vila Real da Praia Grande à Imperial Cidade de Niterói. Revista do Instituto Histórico Geográfico Brasileiro. Vol. 303, abr.-jun. 1974.

STEIN, Stanley. Origens e evolução da indústria têxtil no Brasil. Rio de Janeiro: Editora Campus, 1979. WEHRS, Carlos. Capítulos da memória niteroiense. Rio de Janeiro: 1989 [s.n.] Niterói cidade sorriso: a história de lugar. Rio de Janeiro: Gráfica Vida Doméstica, 1984.

\section{NOTAS}

1. Paulo Alves foi o primeiro prefeito de Niterói, ficando à frente do governo de 4/01/1904 a $8 / 11 / 1904$.

2. Niterói foi capital da província e depois capital do Estado do Rio de Janeiro de 1835 a 1975. Após ter sido palco de violentos combates durante a Revolta da Armada, em 1893, Petrópolis se tornou capital do estado do Rio de Janeiro no intervalo de 1894 a 1903.

3. Referimo-nos aqui ao Plano de Edificação da Vila Real da Praia Grande, de autoria do pintor francês Arnaud Julien Pallière, executado no início do séc. XIX e ao Plano de Urbanização para a Cidade Nova, elaborado pelos engenheiros militares, também franceses, Carlos Rivière Pedro Taulois, em 1841. Novas intervenções urbanas foram realizadas na cidade durante o período republicano, mas o "traçado imperial" (seguindo o traçado de tabuleiro de xadrez) do Plano Pallière, jamais conseguiu ser completamente eliminado. Para mais, ver: CAMPOS, 2004; SOUZA, 1974.

4. Ao contrário do que ocorreu em Campos e Petrópolis, onde a política adotada para a escolha dos prefeitos foi de cooptação, em Niterói, a escolha de Paulo Alves se deu por critérios puramente técnicos, com intuito de neutralizar as forças oposicionistas ao nilismo na cidade (FERREIRA, 1989).

5. O município de São Gonçalo foi criado pelo Decreto estadual no 124, de 22/9/1890. Em 1892, o recém-criado município de São Gonçalo foi reincorporado à Niterói pelo Decreto $\mathrm{n}^{\mathrm{o}} 1$, de 8/5/1892, tornando-se novamente um município através do Decreto no 34, de 17/12/1892. (IBGE, 1958, p. 255). Em 1942, o bairro de Itaipu foi reincorporado à cidade de Niterói, ficando a cidade com um território de $134 \mathrm{~km}^{2}$.

6. Em 1911, a cidade possuía 56.583 habitantes, sendo 48.028 moradores da zona urbana e 8.555 da rural; Em 1919, dos 64.025 habitantes, 56. 053 residiam em áreas urbanas e 7.972 na zona rural (CD-ROM. UFF/ NDC/ CMF/ BN (org.) Relatório de Prefeitos de Niterói (1904-1977); FORTE, 1941).

7. Notadamente, Campos e Petrópolis,tentaram, mais de uma vez, entrar na disputa para substituir Niterói como sede da capital fluminense, sendo que Petrópolis efetivamente conseguiu ocupar o posto de 1894 a 1903.

8. Otávio Carneiro foi prefeito de Niterói de 1914 a 1918.

9. Decreto $\mathrm{n}^{\mathrm{o}}$ 1.085, de 11/12/1907: concedia favores para a empresa que instalasse um moinho em Niterói. (BIBLIOTECA NACIONAL, 1909); Decreto 1.592 de 27 de junho de 1916: estimulava, “(...) com a isenção de tributos a fundação de indústrias novas que busquem a matéria-prima no próprio paiz, lançando assim as bases do futuro industrial do Estado". (BIBLIOTECA NACIONAL, 1916); Lei no 1.191, de 11/11/1925: concedia favores em prol da siderurgia em território fluminense (BIBLIOTECA NACIONAL, 1930); Lei Estadual ํㅡㄴ 1.146 de 20/11/1917: previa a isenção do imposto de indústrias e profissões no prazo de cinco 
anos aos industriais que instalassem seus negócios no estado(BIBLIOTECA NACIONAL, 1917.).; Lei Estadual $\mathrm{n}^{\mathrm{o}} 2.356$ de 20/1/1930: isentava de impostos estaduais e municipais por dez anos aos industriais que viessem a estabelecer na zona portuária de Niterói (PESSANHA, 1988).

10. Instalado em Niterói em 1845, o Estaleiro Mauá foi uma iniciativa de Irineu Evangelista de Souza, o Barão de Mauá. Considerado o maior empreendimento privado do gênero na época, o estaleiro chegou a ter cerca de 600 operários, sendo aproximadamente $1 / 4$ deles escravizados (MATTOS, 2008; MOMESSO, 2007).

11. A fábrica de fumos "Veado" foi fundada em 1874, na cidade do Rio de Janeiro. Transferida para Niterói ainda no Império, a fábrica teve uma produção destacada no cenário nacional até a segunda década do século XX, sendo posteriormente absorvida pela Souza Cruz.

12. Cia. Manufatora Fluminense: 1.000 operários; Fábrica de Fósforos de Antônio Migliora: 460 operários; Cia.Fabril São Joaquim: 460 operários; Fábrica de Fósforos Brazil: 425; Fábrica de Fósforos Brilhante: 230 operários; Fábrica de fumos "Veado": 130. Sobre a fábrica Fiat Lux, localizamos a informação de que em 1912 contava com mais de 1.000 operários (CD-ROM. UFF/ NDC/ CMF/ BN (org.). Relatório de Prefeitos de Niterói (1904-1977), 1904; 1912; BIBLIOTECA NACIONAL, 1891 e 1903; LLOYD'S GREATER BRITAIN PUBLISHING COMPANY LTDA, 1913; WEHRS, 1984; WEHRS, 1989).

13. Criada pelo Decreto $\mathrm{n}^{\circ} 208$ de 19 de fevereiro de 1890.

14. A Cia. Cantareira controlou o serviço de bondes elétricos até 1951 e de barcas até 1959. Após o episódio do chamado "Quebra-quebra das barcas", a Companhia - então controlada pelo Grupo Carreteiro desde o início dos anos 1950 - foi encampada pelo governo. Nos anos 1940, a Cantareira passou a sofrer concorrência de duas empresas menores: a Frota Barreto e a Frota Carioca. A Cia. Cantareira possuía também um pequeno estaleiro construído no início do século XX no bairro do Gragoatá, para reparos navais de sua frota. (WEHRS, 1984; NUNES, 2000).

15. De1897 a 1950, a empresa era controlada pela The Leopoldina Railway Company Limited, tendo sido encampada a partir dessa data.

16. Após a Cia. Cantareira e Viação Fluminense (CCVF) ser adquirida pelo Grupo Carreteiro, o serviço de bondes elétricos passou a ficar a encargo do governo do estado que criou através do Decreto ํo 4.104 de 12/2/1952, o Serviço de Viação de Niterói e São Gonçalo (SERVE). Segundo Carlos Wehrs, a estatal passou a circular na cidade os primeiros troley-buses, passando a partir de 1967, a dedicar-se apenas ao transporte coletivo movido à gasolina (WEHRS, 1984).

17. Em 1927, quando foi inaugurado, o porto foi entregue à Companhia Brasileira de Portos. Para mais, ver: COSTA, 2010.

18. A cidade de Niterói também recebeu migrantes oriundos de estados do nordeste brasileiro. Contudo, a presença destes se tornou mais expressiva a partir da ampliação da rede rodoviária brasileira interligando diferentes estados da federação. No caso de Niterói, a construção da Ponte Rio-Niterói e da BR 101, na década de 1970, tiveram um papel decisivo no aumento do número de migrantes nordestinos na cidade.

19. Maria Rita da Silva Guimarães identificou que entre 1940 e 1950 ocorreu um decréscimo significativo de pessoas ocupadas da agricultura, pecuária e silvicultura no estado do Rio de Janeiro: de $58 \%$ em 1940 para $41 \%$ em 1950. A população urbana, por seu turno, cresceu de $38 \%$ para $48 \%$ neste mesmo período de referência (GUIMARÃES, 1957. p. 462).

20. Quanto à população operária de Niterói, Pedro Geiger (1956) chama a atenção para a possibilidade do município São Gonçalo (que possuía uma população operária de 13.263 e tinha apenas 6.893 trabalhando em suas fábricas), incrementar ainda mais este número na capital fluminense. Segundo o autor, estes trabalhadores se dirigiam para Niterói e Rio de Janeiro para trabalhar, “(...) atestando o caráter suburbano da cidade” (p. 499). 
21. Ainda de acordo com dados recolhidos neste recenseamento, dos habitantes de Niterói: 11.983 de pessoas eram oriundas do Distrito Federal, 5.755 de Minas Gerais, 6.838 de diferentes estados do nordeste, 2.470 de São Paulo, 2.116 do Espírito Santo, 1.722 dos estados da região sul e 364 do centro-oeste. Os estrangeiros residentes na cidade contabilizavam um total de 8.461 pessoas e mais 1.058 estrangeiros naturalizados.

22. Distrito Federal: $1.171 \mathrm{~km}^{2}$; Niterói: $134 \mathrm{~km}^{2}$ (IBGE, 1951).

23. $O$ bairro do Barreto também integra a zona norte da cidade.

\section{RESUMOS}

Este trabalho tem como objetivo apresentar alguns aspectos da ocupação industrial e operária da cidade de Niterói, buscando analisar o tipo de indústria, a sua concentração espacial, bem como refletir sobre o processo de urbanização e modernização da cidade. Tendo ocupado o posto de capital do estado do Rio de Janeiro até a fusão deste estado com antiga Guanabara em 1975, Niterói buscou ao longo dos anos, consolidar-se frente ao posto de capital fluminense, buscando ao mesmo tempo administrar a influência que a cidade do Rio de Janeiro - então capital federal exercia-lhe. Concentrando em seu território uma grande quantidade de indústrias desde as primeiras décadas do século XX, a capital fluminense se tornou polo de atração de fábricas e trabalhadores, oriundos, sobretudo do interior do estado do Rio de Janeiro, configurando dessa maneira, o que estamos denominando de "região industrial e operária" de Niterói.

This papper aims to present some aspects of the industrial and working occupation of the city of Niterói, seeking to analyze the type of industry, its spatial concentration, as well as reflect on the process of urbanization and modernization of the city. Having occupied the capital of the state of Rio de Janeiro until the merger of this state with old Guanabara in 1975, Niterói sought over the years to consolidate itself in front of the state capital of Rio de Janeiro, while at the same time managing to influence the city of Rio de Janeiro - then the federal capital - exercised him. Concentrating in its territory a great amount of industries since the first decades of the twentieth century, the capital of Rio de Janeiro became a center of attraction for factories and workers, mainly from the interior of the state of Rio de Janeiro, thus configuring what we are calling of "industrial and worker region" of Niterói.

Este trabajo tiene como objetivo presentar algunos aspectos de la ocupación industrial y obrera de la ciudad de Niterói, buscando analizar el tipo de industria, su concentración espacial, así como reflexionar sobre el proceso de urbanización y modernización de la ciudad. Habiendo ocupado el puesto de capital del estado de Río de Janeiro hasta la fusión de este estado con antigua Guanabara en 1975, Niterói buscó a lo largo de los años, consolidarse frente al puesto de capital fluminense, buscando al mismo tiempo administrar la influencia que la ciudad de Río de Janeiro-entonces capital federal- le ejercía. En el caso de los países industrializados, la mayoría de los países de América Latina y el Caribe se han convertido en una de las principales ciudades del mundo. de "región industrial y obrera" de Niterói.

Ce travail vise à présenter certains aspects de l'occupation industrielle et ouvrière de la ville de Niterói, en cherchant à analyser le type d'industrie, sa concentration spatiale, ainsi qu'à réfléchir sur le processus d'urbanisation et de modernisation de la ville. Après avoir occupé le poste de capitale de l'état de Rio de Janeiro jusqu'à la fusion de cet état avec celui de Guanabara en 1975, 
Niterói a cherché au fil des ans à se consolider devant la capitale de Rio de Janeiro, tout en réussissant à gérer l'influence que la ville de Rio de Janeiro - alors capitale fédérale - exerçait sur elle. Concentrant sur son territoire une grande quantité d'industries depuis les premières décennies du XXe siècle, la capitale de Rio de Janeiro est devenue un centre d'attraction pour les usines et les travailleurs, provenant principalement de l'intérieur de l'État de Rio de Janeiro, configurant ainsi ce que nous appelons de "région industrielle et ouvrière" de Niterói.

ÍNDICE

Mots-clés: industrialisation; urbanisation; région; Niterói.

Keywords: industrialization; urbanization; region; Niterói.

Palabras claves: industrialización; urbanización; región; Niterói.

Palavras-chave: industrialização; urbanização; região; Niterói.

\section{AUTOR}

\section{LUCIANA PUCU WOLLMANN}

Doutora em História Política e Bens Culturais pelo CPDOC/FGV e professora da rede municipal e estadual de ensino do Rio de Janeiro. E-mail: luwollmann@yahoo.com.br 